\title{
Free mica grains in crushed rock aggregates
}

\author{
Karl-Johan Loorents · Eva Johansson • \\ Håkan Arvidsson
}

Received: 22 September 2006/ Accepted: 6 January 2007

(C) Springer-Verlag 2007

\begin{abstract}
Enrichment of free mica (i.e. as monomineralic grains) in the fine fraction of crushed rock aggregates affects the quality of the aggregate end product. Granitoid rock from the Svecofennian Province were used as being representative of crushed rock aggregates commonly used for construction purposes. The results reveal a general trend of enrichment of mica for finer fractions. For the coarse grained rock a peak occurs at $0.25-0.5 \mathrm{~mm}$ followed by a decrease in the amount of free mica; for grains $<0.063 \mathrm{~mm}$ there is an increase. The general trend and peak are correlated to the microstructural characteristics of the samples.
\end{abstract}

Keywords Crushed rock aggregates - Free mica ·

Monomineralic grain

Résumé L'enrichissement en micas libres (c.à.d. en grains mono-minéraux) dans la fraction fine des granulats de roche concassée affecte la qualité du produit fini. Une roche granitoïde de la province svecofennienne a été utilisée comme représentative des granulats de roche concassée communément utilisés pour la construction. Il apparait une tendance générale à l'enrichissement en micas des fractions fines. Pour la fraction grossière un pic de concentration en micas libres apparaît pour la fraction $0.25-0.50 \mathrm{~mm}$. Puis cette concentration diminue pour augmenter à nouveau pour la fraction $<0.063 \mathrm{~mm}$. La tendance générale et les pics de

K.-J. Loorents $(\bowtie) \cdot$ H. Arvidsson

VTI, 58195 Linköping, Sweden

e-mail: karl-johan.loorents@vti.se

E. Johansson

Department of Civil and Environmental Engineering,

Luleå University of Technology,

97187 Luleå, Sweden concentration sont corrélés avec les caractéristiques microstructurales des échantillons.

Mots clés Granulats de roche concassée - Micas libres . Grains mono-minéraux

\section{Introduction}

Free mica (i.e. monomineralic grains) in crushed rock aggregates, for construction purposes (Smith and Collis 2001), affects the quality of the aggregate end product. Nieminen and Uusinoka (1986) show a correlation between the mineral composition of the fine fraction and the quality of the unbound base material. Their research points out that an unbound layer, constructed with a material containing a fine fraction of a "larger" specific surface area (e.g. clay minerals and micas), implies a high risk of constructional deterioration. Hakim and Said (2003) and Miskovsky (2004) show a material deterioration of bituminous mixtures connected with an increase in the amount of micas in the fine fraction $(<2 \mathrm{~mm})$. A similar relationship has been described by Lagerblad (2005) for fine fractions used in concrete.

Miskovsky (2004) shows a general trend of increase in the amount of free mica when comparing narrow grain fractions, having analysed five samples of granitoid rocks with varying mica content. Whereas Lagerblad (2005) states that there is a steady increase in the amount of free mica with a peak for grain sizes between 0.125 and $0.25 \mathrm{~mm}$, for smaller grains no enrichment was detected. The study was based on 17 samples of granitoid rocks.

The aim of this study is to enhance an understanding of how the amount of free mica varies within granitic crushed rock aggregates, with special attention to the correlation of the microstructural characteristics of rock samples 
(Passchier and Trouw 1996; Prikryl 2001). The rock samples used in this study are representative of the common crushed rock aggregates used for construction purposes and have been prepared according to the standard laboratory routines. The rock samples have been analysed on their free mica content. The microstructural description of the rock samples has improved the interpretation of the behaviour of free mica in crushed rock aggregates.

\section{Materials and methods}

Rock samples were collected from two areas of the Svecofennian Province granitoids. Samples 1 and 2 were extracted from the same quarry, situated in the south east of Sweden, and sample 3 was obtained from a road cutting located in the central part of Sweden.

To limit factors that may influence the breakage of the rock (e.g. the release of free mica during crushing), rock samples of similar microstructural characteristics were preferred. The samples were all more or less undeformed (microstructurally isotropic). Microstructural difference is mainly indicated by the grain size distribution and to a lesser extent by aggregates of grains, grain-size, shape and boundary (Passchier and Trouw 1996). Samples 1 and 2 had a similar mineralogical composition whereas sample 3 was enriched in mica compared to the other study samples. Mineral alteration (before the process of weathering; Delvigne 1998) is mainly limited to serecitic alteration of feldspars. None of the study samples showed any change due to weathering.

\section{Sample 1}

Sample 1 (granite) was weakly foliated (mineral orientation defined by small grained biotite), medium grained (1-2 mm; Gillespie and Styles 1999) and grey to red (Fig. 1). A complete gradation (seriate) of fine- to mediumgrained grain size distribution with irregular, lobate grain boundaries (interlobate) describes the microstructure. The mineralogical composition was quartz $>$ K-feldspar $>$ plagioclase $>$ muscovite $>$ biotite $>$ chlorite with accessory opaque minerals, apatite, epidote and zircon (Table 1). The quartz grains had undulose extinction and an anhedral shape of grains. The K-feldspar (anhedral-subhedral) had welldeveloped microcline (scotch plaid) twinning; a few megacrysts were present. The plagioclase (subhedralanhedral) had a fairly well-developed polysynthetic twinning (albite) and a less common combined albite and pericline twinning. Some sericite alteration was seen in the majority of the plagioclase. The muscovite was generally coarser grained than the biotite; the latter showing some alteration to chlorite.

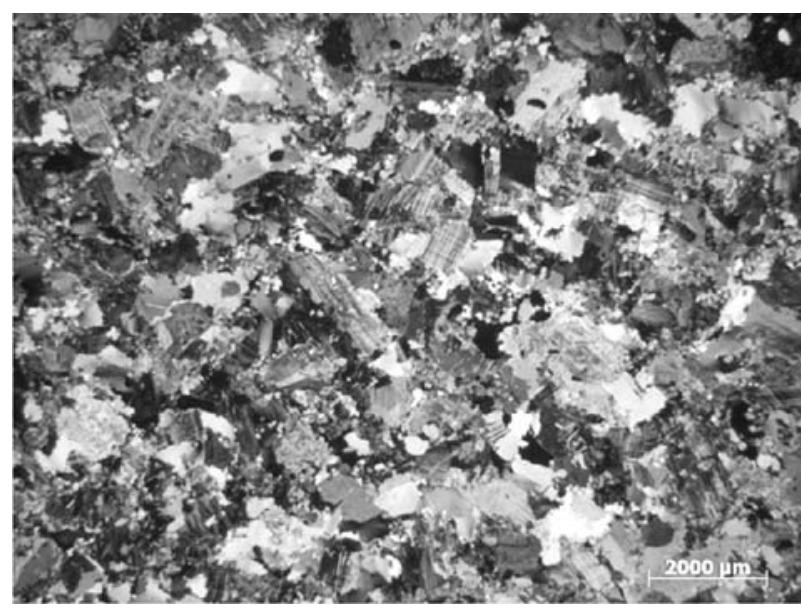

Fig. 1 Sample 1

Sample 2

As seen in Table 1, sample 2 (Fig. 2) was in general similar to sample 1 although with some differences in mineral composition and to a lesser extent grain size distribution.

\section{Sample 3}

Sample 3 (monzogranite) was a white and black, coarsegrained ( $>2.5 \mathrm{~mm}$; Gillespie and Styles 1999) massive rock with a mineralogical composition K-feldspar > quartz > plagioclase $>$ biotite (Fig. 3). Accessory minerals included titanite, sericite, kaolinite, zircon, chlorite, opaque and apatite (Table 1). A seriate distribution of grains with an interlobate shape of grain aggregates describes the microstructure. Plagioclase (subhedral-anhedral) commonly had well-developed polysynthetic twinning (albite) and less commonly combined albite and pericline twinning. Some sericite alteration of the plagioclase was present. K-feldspar (subhedral-anhedral) showed sparse intergrowth of quartz (granophyric texture). Megacrysts of K-feldspar were present. The quartz grains (anhedral) had undulose extinction and "sub grains" that may indicate a compressive deformation. The biotite showed a slight alteration to chlorite.

\section{Sample preparation}

Sample breakage was achieved using a primary and a secondary laboratory jaw crusher. The primary discharge aperture (setting) was $40 \mathrm{~mm}$ and the secondary crusher had a setting of $15 \mathrm{~mm}$. For each type of rock, a sample similar in shape was used for crushing with the following data for weight, density and volume: sample $1-2.58 \mathrm{~kg}$, $2.64 \mathrm{Mg} / \mathrm{m}^{3}$ and $0.98 \mathrm{dm}^{3}$; sample 2-2.70 kg, $2.64 \mathrm{Mg} / \mathrm{m}^{3}$ 
Table 1 Mineralogical composition (in vol.\%) and grain size distribution of the main minerals

\begin{tabular}{lllllllll}
\hline & Quartz & Plagioclase & K-feldspar & Biotite & Chlorite & Muscovite & Opaque & Assessory \\
\hline Sample 1 & 40 & 14 & 36 & 3 & 3 & 4 & 0.2 & 0.2 \\
Grain size $(\mathrm{mm})$ & $0.6-1.5$ & $1.4-2.9$ & $1.2-3.7$ & $0.4-0.8$ & - & $0.6-1.6$ & - & - \\
Sample 2 & 37 & 14 & 37 & 4 & 1 & 7 & Trace & 1.0 \\
Grain size $(\mathrm{mm})$ & $0.7-1.6$ & $1.4-3.2$ & $1.4-2.5$ & $0.6-1.3$ & - & $0.9-1.6$ & - & - \\
Sample 3 & 28 & 25 & 27 & 19 & - & - & Trace & 1.4 \\
Grain size $(\mathrm{mm})$ & $0.9-2.3$ & $1.5-3.2$ & $1.7-2.9$ & $0.9-2.5$ & - & - & - \\
\hline
\end{tabular}

The mineral mode is based on point counting using a polarising microscope

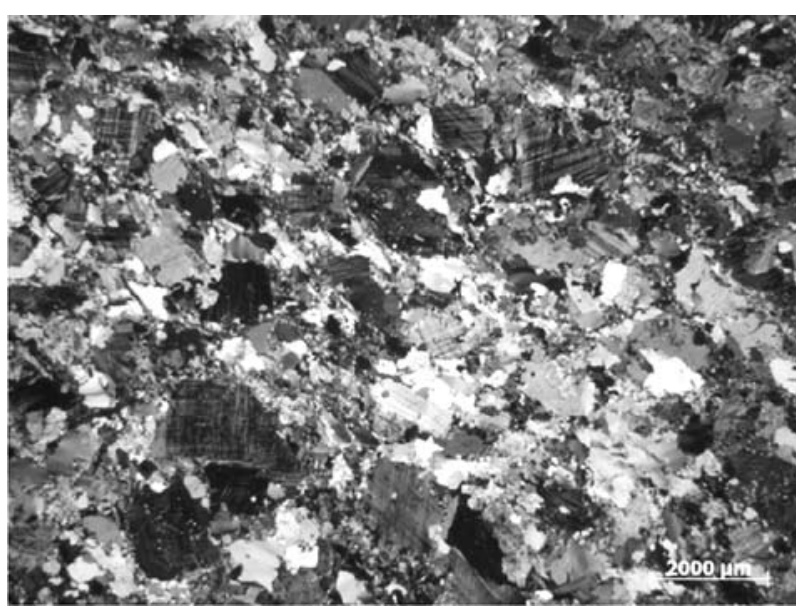

Fig. 2 Sample 2

and $1.02 \mathrm{dm}^{3}$; sample $3-2.55 \mathrm{~kg}, \quad 2.68 \mathrm{Mg} / \mathrm{m}^{3}$ and $0.95 \mathrm{dm}^{3}$. The grain size distribution for each crushed sample was obtained by dry sieving according to EN 933-1 (Fig. 4). Additional sieving was undertaken for grains $<63 \mu \mathrm{m}$ (sample sizes were approximately $20 \mathrm{~g}$ ). Sieves were weighed before and after sieving to measure the amount of material that remained on the sieve (Table 2). Compressed air was used to clean the sieves between each sieving cycle. From the sieving, the following grain size fractions were collected for analysis: 0.5-1, $0.25-0.5, \quad 0.125-0.25, \quad 0.063-0.125 \mathrm{~mm}, \quad 42-63, \quad 24-42$ and $<24 \mu \mathrm{m}$.

Free mica content

To estimate the amount of free mica in the collected grain size fractions two methods were used generally following RILEM AAR (Sims and Nixon 2003).

For size fractions $0.5-1,0.25-0.5$ and $0.125-0.25 \mathrm{~mm}$ samples were collected and an additional quartering undertaken in order to obtain representative, homogeneous samples. Grains were grouped and counted (stereoscopic microscope, Technique 1) on the basis of mineralogy into

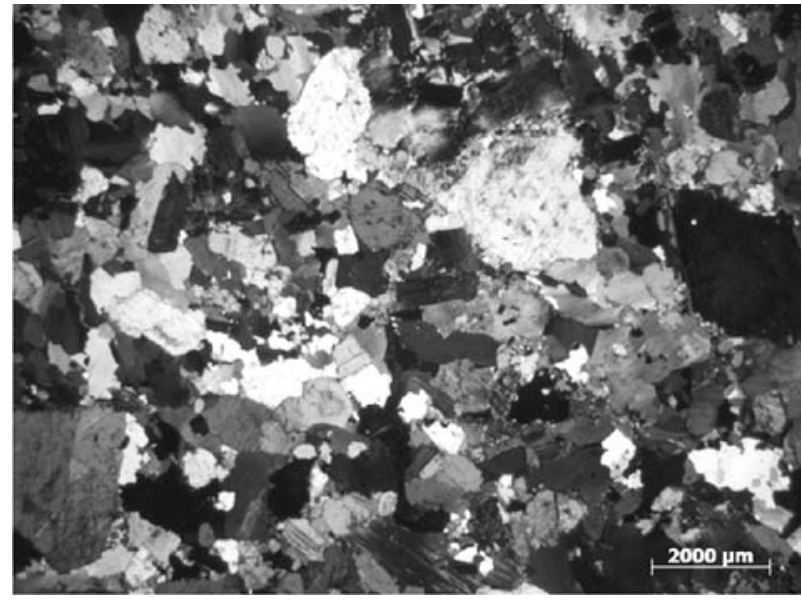

Fig. 3 Sample 3

muscovite, biotite and others where appropriate. All grains in the collected and reduced (quartered) sample were counted (Table 3).

With Technique 2, a polarizing microscope and a point counting apparatus were used for $0.5-1,0.25-0.5,0.125$ $0.25,0.063-0.125 \mathrm{~mm}, 42-63,24-42$ and $<24 \mu \mathrm{m}$. Thin sections were prepared as grain mounts (Nesse 2004) from 2-4 g of crushed sample for each collected grain fraction. Counting was performed in the same way as for the coarser grains (Table 3).

\section{Discussion}

Prior to sieving, it was not clear whether it would be possible to obtain/collect representative samples, particularly for grain fractions $<63 \mu \mathrm{m}$. However, weighing the sieve before and after sieving (Table 2) and a microscopic optical control of the mesh gave a useful and more objective indication of the material passing through the sieves.

Technique 1 was chosen for certain grain fractions, as this method ensures that monomineralic material, or aggregates dominated by one mineral, is properly grouped 
Fig. 4 Grain size distribution of the three samples after crushing into two steps

Table 2 Sieving of materials $<63 \mu \mathrm{m}$

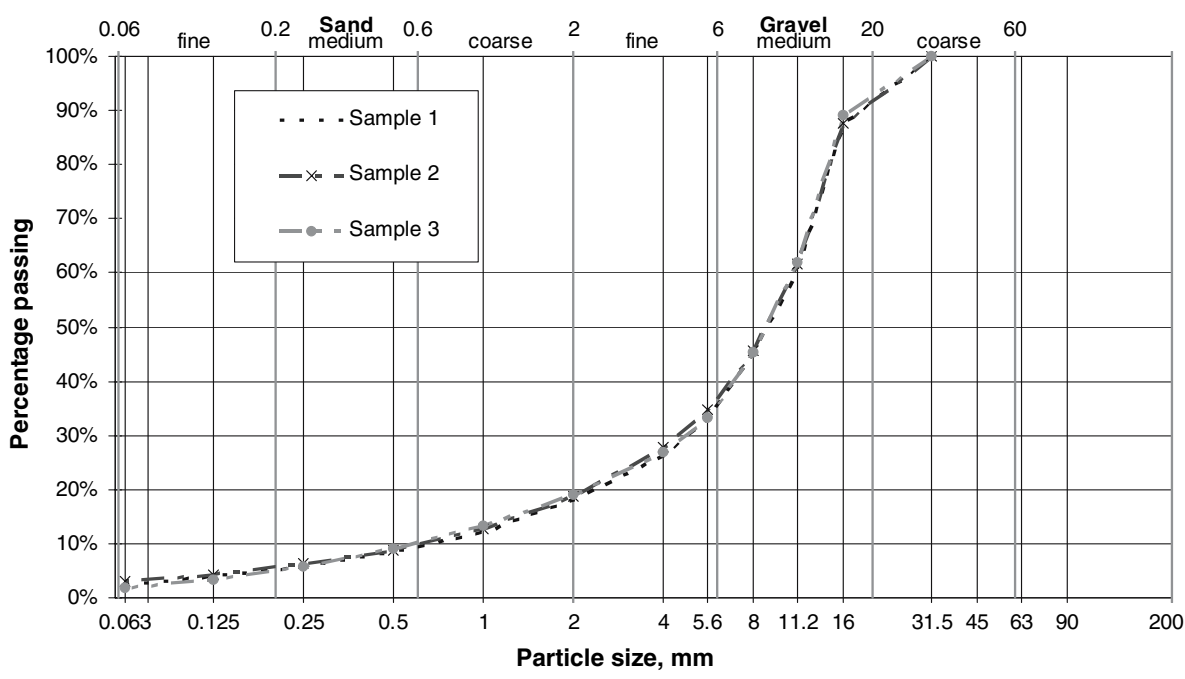

\begin{tabular}{|c|c|c|c|c|c|c|}
\hline \multirow[t]{2}{*}{ Sieve $(\mu \mathrm{m})$} & \multicolumn{3}{|c|}{ Passing material sample $(\%)$} & \multicolumn{3}{|c|}{ Fasten material $(\mathrm{g})$} \\
\hline & 1 & 2 & 3 & 1 & 2 & 3 \\
\hline 63 & 99.6 & 99.2 & 99.7 & 0.07 & 0.07 & 0.06 \\
\hline 42 & 72.4 & 80.6 & 71.4 & 0.04 & 0.03 & 0.03 \\
\hline 24 & 32.7 & 40.6 & 37.1 & 0.04 & 0.04 & 0.05 \\
\hline
\end{tabular}

and counted. Technique 1 is of limited value for coarser grains, as the power of resolution of the equipment is not sufficient for the finer fractions analysed in this study. However, the results from Techniques 1 and 2 are not directly comparable, as the preparation of the samples and analysing technique differ. With Technique 1 , a sample is retrieved from the collected batch and should contain a minimum number of grains to be representative of the batch; it is also important that all grains of the sample are counted. Considering mineral separation there is a risk of biased sampling with this method. For two batches, double samples were counted to assess precision. This indicated that the counting varied by up to $10 \%$.

The formation of free mineral phases or monomineralic grain constituents during breakage by crushing is mainly dependent on the mineralogical composition (strength of minerals), grain boundaries and the grain size of the rock. Thus for a coarse grained rock monomineralic grains will comprise a larger fraction of "coarser" grains. This relationship ensures monomineralic grain constituents for "finer" grain fractions and validates the use of Technique 2 , especially for medium and coarser grained rocks.

Technique 2 also uses a minimum number of grains to ensure a statistical significance, but provides a more robust methodical handling as the sample (thin section) is impregnated with epoxy resin. With this method (point counting), counts indicate the presence of a certain mineral phase, but make no distinction between monomineralic and aggregate (composed of at least two minerals) grains. The use of optical microscopy for fractions $<63 \mu \mathrm{m}$ has its practical limitations, as mineral identification may be hard to perform. However, as analysing and counting always started with the coarsest fraction, and the mineralogy of the sample was well known, the method proved useful.

Thus Technique 1 was used to ensure counting of free mica grains and partly as a comparison between the methods. The main emphasis was on Technique 2 as this provides one "continuous" counting method for all size fractions analysed in this paper.

The three samples studied are all igneous rocks. Considering microstructural characteristics, samples 1 and 2 have similar mineral composition and grain size, while sample 3 differs mainly in grain size. Samples 1 and 2 are medium grained and sample 3 coarse grained. The trend line of sample 3 (Fig. 5) generally shows higher amounts of free mica for coarser grain fractions, indicating that the amount of free mica depends on initial mineral content and grain size of the rock.

Figure 5 (see Table 3) depicts the varying free mica content for the samples, dependent on grain size. Comparing the trend lines, using grain fractions 0.063 $0.125 \mathrm{~mm}$ as a "divider" gives quite different relationships for the $<0.063$ and $>0.125 \mathrm{~mm}$ grain fractions. For grains $>0.125 \mathrm{~mm}$ the relationship is less consistent while for grain fractions $<0.063 \mathrm{~mm}$ a uniform trend of increase is displayed. This difference correlates with the initial grain size of the rock and content (modal vol.\%) of mica. It is suggested that coarse grained rocks follow the trend line of 
Table 3 Mica content (in particle and vol.\%) of sample according to analysed grading fraction together with total number of grains counted

\begin{tabular}{|c|c|c|c|c|c|c|c|c|}
\hline \multirow[t]{2}{*}{ Grain size } & $\mathrm{Bt}$ & Ms & $\%$-Mica & Count & $\mathrm{Bt}$ & Ms & $\%$-Mica & Count \\
\hline & \multicolumn{4}{|c|}{ Technique 1} & \multicolumn{4}{|c|}{ Technique 2} \\
\hline \multicolumn{9}{|l|}{ Sample 1} \\
\hline $0.5-1(\mathrm{~mm})$ & 1 & 7 & 8 & 215 & 2.8 & 7.3 & 10.2 & 1,704 \\
\hline $0.25-0.5$ & 7 & 5 & 12 & 526 & 5.6 & 7.6 & 13.2 & 1,787 \\
\hline $0.125-0.25$ & 8 & 8 & 16 & 571 & 6.6 & 7.6 & 14.1 & 1,999 \\
\hline $0.063-0.125$ & & & & & 5.2 & 8 & 13.3 & 2,157 \\
\hline $42-63(\mu \mathrm{m})$ & & & & & 6 & 9 & 15 & 583 \\
\hline $24-42$ & & & & & 10 & 14 & 24 & 567 \\
\hline$<24$ & & & & & 14 & 19 & 33 & 525 \\
\hline \multicolumn{9}{|l|}{ Sample 2} \\
\hline $0.5-1(\mathrm{~mm})$ & 1 & 6 & 7 & 299 & 4.2 & 7.1 & 11.2 & 1,659 \\
\hline $0.25-0.5$ & 3 & 6 & 9 & 467 & 3.8 & 8.3 & 12.0 & 1,695 \\
\hline $0.125-0.25$ & 8 & 9 & 17 & 773 & 6.4 & 8.7 & 15.1 & 1,925 \\
\hline $0.063-0.125$ & & & & & 6.9 & 8.2 & 15.0 & 2,022 \\
\hline $42-63(\mu \mathrm{m})$ & & & & & 6 & 8 & 14 & 539 \\
\hline $24-42$ & & & & & 13 & 13 & 26 & 558 \\
\hline$<24$ & & & & & 17 & 17 & 34 & 508 \\
\hline \multicolumn{9}{|l|}{ Sample 3} \\
\hline $0.5-1(\mathrm{~mm})$ & 24 & & 24 & 368 & 18.8 & & 18.8 & 1,834 \\
\hline $0.25-0.5$ & 31 & & 31 & 420 & 21.8 & & 21.8 & 1,704 \\
\hline $0.125-0.25$ & 22 & & 22 & 699 & 19 & & 19.0 & 1,971 \\
\hline $0.063-0.125$ & & & & & & & 14.2 & 2,085 \\
\hline $42-63(\mu \mathrm{m})$ & & & & & 17 & & 17 & 557 \\
\hline $24-42$ & & & & & 20 & & 20 & 568 \\
\hline$<24$ & & & & & 36 & & 36 & 536 \\
\hline
\end{tabular}

Bt biotite, $M s$ muscovite,

$\%$-Mica total \% mica in sample, Count total number of grains/ points counted reach a "critical", grain fraction (e.g. $<0.063 \mathrm{~mm}$ ) before further breakage continues.

Among the studied samples, sample 3 contains the highest initial content of mica and the coarsest grains (Table 1). The connection between the initial mineral content of the rock and the content of free mica in the grain fractions correlates well for fractions $>0.125 \mathrm{~mm}$ (Fig. 5). For grain fractions $<0.063 \mathrm{~mm}$ the influence of the initial mica content is no longer perceived. The peak of sample 3 for grains $>0.125 \mathrm{~mm}$ indicates that there is a relationship between initial grain size and grain size fraction, based on the assumption that mica grains are less mechanically competent than, for instance, quartz and thus break more readily into "smaller' particles due to mechanical stress. The three samples used in this study provide a somewhat sparse basis for reasoning, thus a review of some data in the literature on free mica in crushed rock aggregates for construction purposes was motivated. Miskovsky (2004), using a polarizing microscopy and the point-count method, showed a general increase in the amount of free mica for the finer fractions $(<0.074,0.074-0.25$ and $0.25-2 \mathrm{~mm})$, analysing five samples of granitoid rocks with varying mica content (5.6-33 vol.\%; Fig. 6). The result of the 


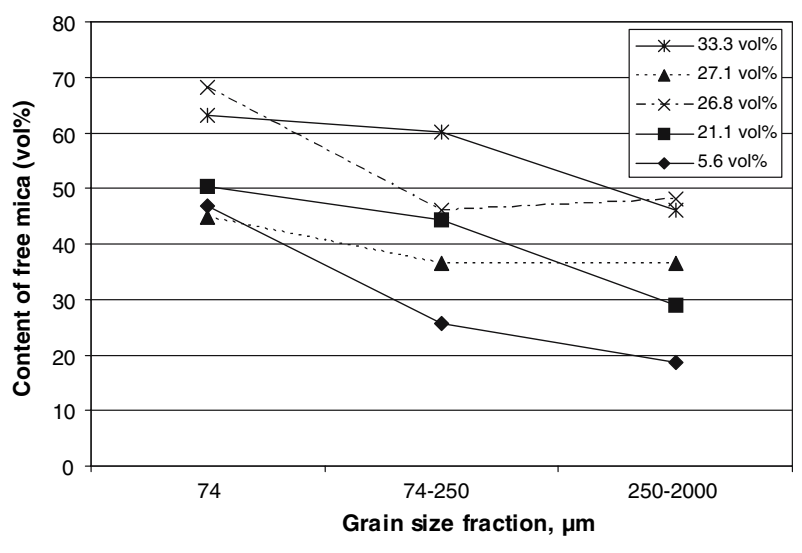

Fig. 6 The content of free mica in the collected fractions; the samples are sorted into initial content of mica of the uncrushed rock (modified after Miskovsky 2004)

study suggests the mica enrichment in the grain size fractions: $0.25-2 \mathrm{~mm}, 8-21.2 \mathrm{vol} . \%$; 0.074-0.25 mm, 9.5-34.6 vol. $\%$ and $<0.074 \mathrm{~mm}, 17.8-41.4$ vol.\%.

Despite the fact that the collected and analysed grain size fractions of Miskovsky and the present study are not directly comparable, the two studies show the same tren$\mathrm{d}$-an enrichment of mica with finer fractions. Furthermore, the same method is being used (point counting) which additionally strengthen the results of the studies. In this kind of study, a narrows grain size fraction is preferred as this increases the resolution and provides more data on the behaviour of rock breakage by crushing.

Microstructural comparison between the studies is not possible as no structural information is provided by Miskovsky (2004) except that the samples were granitoid rocks.

Lagerblad (2005) states that there is no enrichment of mica for the finer grain fractions $(<0.125 \mathrm{~mm})$ after analysing 17 samples of granitoid rocks, using X-ray powder diffraction (XRD) and scanning electron microscope (SEM) analyses for materials $<75 \mu \mathrm{m}$ (5 samples) and the point-count method for fractions; 75-125, 125-250, 250$500,500-1,000,1,000-2,000 \mu \mathrm{m}$ (Fig. 7). Lagerblad's study implies a peak in the amount of free mica for the $125-250 \mu \mathrm{m}$ fraction and then, based on results from the XRD, SEM and point counting analysis, a possible trend of lower amounts of free mica with finer fractions.

The point counting method used by Lagerblad and the present study is similar, thus the results are comparable. The point counting data from Lagerblad's study is presented in Fig. 7, which has been modified and grouped into fine, medium and coarse grained rock in an attempt to clarify any microstructural correlations. The (trend) curves in Fig. 7 verify a peak for medium and coarse grained rocks, possibly with an initial "higher" content of mica
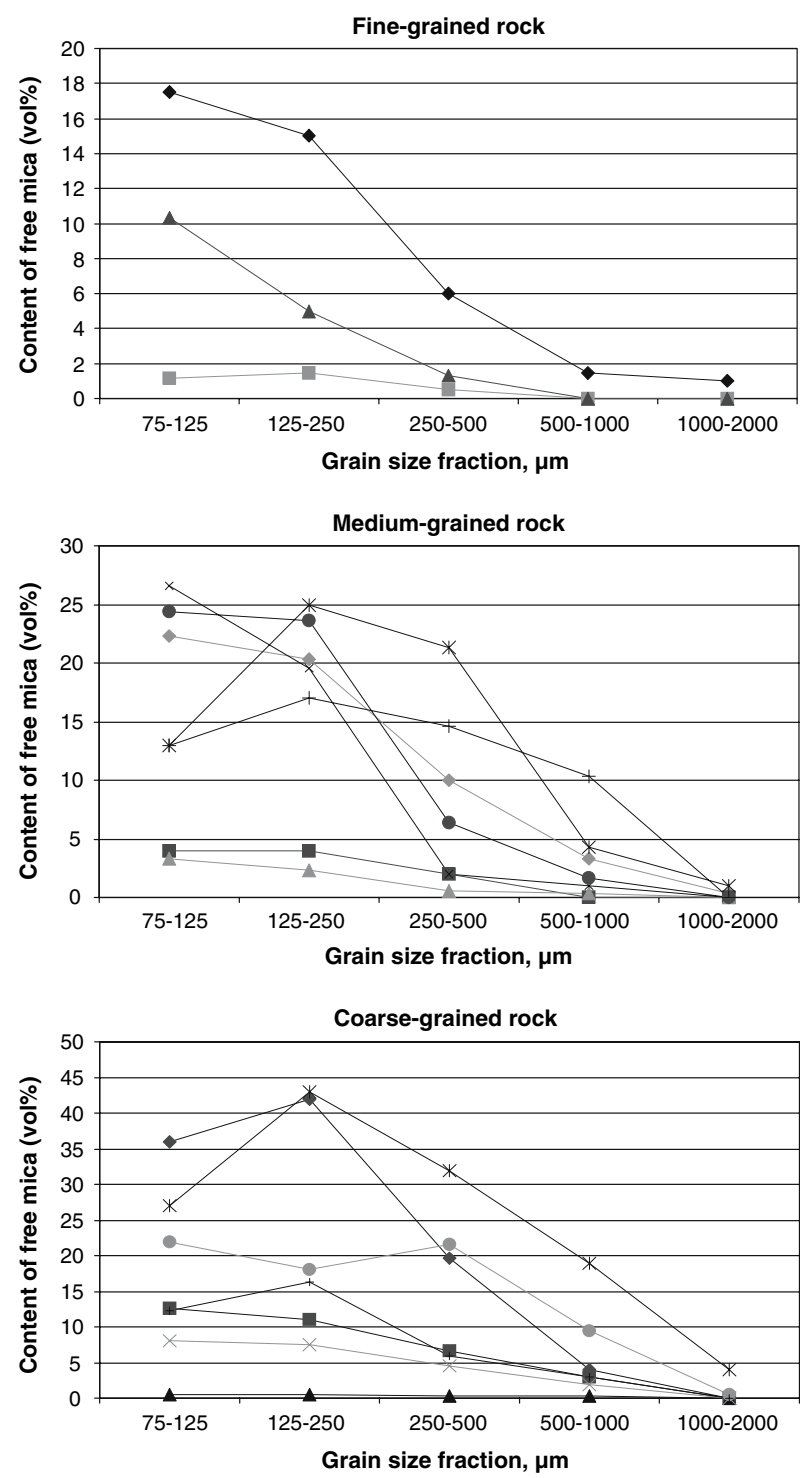

Fig. 7 The content of free mica for collected grain fractions for fine, medium and coarse grained rock (modified after Lagerblad 2005)

Table 4 Content of biotite and chlorite (vol.\%) for medium and coarse-grained samples

\begin{tabular}{llllll}
\hline & Medium & Coarse & Medium & Medium & Medium \\
\hline$<38 \mu \mathrm{m}$ & & & & & \\
Biotite & 16 & 6.1 & & 11.1 & 15.6 \\
Chlorite & 7.2 & 1.9 & & & 15.6 \\
Grains & 188 & 212 & 196 & 206 & 173 \\
$<38-63 \mu \mathrm{m}$ & & & & & \\
Biotite & 11 & & 2.3 & 14.8 & 11.5 \\
Chlorite & & & & & 12 \\
Grains & 209 & 219 & 219 & 203 & 209 \\
\hline
\end{tabular}

Grains indicate the total number of counts 
although Lagerblad gives no information on the initial mineral composition. The analysis from the present study verifies a peak for the coarse grained sample 3 (Fig. 3). Considering the results from Miskovsky (2004), Lagerblad (2005) and the present study, it is assumed that the position (grain size fraction) and the height of the peak (content of free mica) depend on the rock's initial mineral composition and mean grain size thus indicating the importance of microstructural characteristics for the variation in free mica in crushed rock aggregates.

Lagerblad also carried out SEM analysis on five samples for fractions $<38$ and $37-63 \mu \mathrm{m}$. As seen in Table 4 , the results do not indicate a uniform "stronger" trend towards an increase or decrease in the content of mica for the analysed fractions.

To further understand the variation of free mica for finer fractions, Lagerblad used semi-quantitative XRD counting techniques to obtain an indication of the mineral content for fractions $<38$ and $37-63 \mu \mathrm{m}$. Peak intensities, correlated to SEM analysis (Table 4), were used to assess mineral variations. As the method is semi-quantitative, any variations are at best an estimation based on trends, but appear to show lower amounts of free mica with the finer fractions.

\section{Conclusion}

On the basis of the analytical data presented in this study, there is a general trend towards the enrichment of mica in the finer fraction of the fine grained rocks; with medium and coarse grained rocks, the amount of free mica generally peaks within the fraction $125-250 \mu \mathrm{m}$.

This work has focused on igneous rocks but crushed rock aggregates come from a wide array of rock types hence further research is needed to establish if a similar situation occurs with metamorphic and sedimentary rocks.

Acknowledgments VTI, the Swedish National Road and Transport Research Institute funded this work.

\section{References}

Delvigne JE (1998) Atlas of micromorphology of mineral alteration and weathering. The Canadian Mineralogist, special publication 3, $494 \mathrm{pp}$

Gillespie MR, Styles MT (1999) BGS rock classification scheme, vol 1. In: Classification of igneous rocks, 2nd edn. British Geological Survey Research Report, RR 99-06

Hakim H, Said S (2003) Glimmer i bitumenbundna beläggningar-Inverkan av fina, fria glimmerkorn. VTI notat 8-2003, Linköping

Lagerblad B (2005) Krossat berg som ballast till Betong, Slutrapport. MinBas projekt nr 2,2 Framtida betong-Delprojekt 2,23 Utnyttjande av alternativa typer av ballast i betong. MinBas Område 2, Rapport 2:19, Stockholm

Miskovsky K (2004) Enrichment of fine mica originating from rock aggregate production and its influence on the mechanical properties of bituminous mixtures. ASM Int J Mater Eng Perfor 13(5):607-611

Nieminen P, Uusinoka R (1986) Influence of quality of fine fractions on engineering geological properties of crushed aggregate. Bull Int Assoc Eng Geol 33

Nesse WD (2004) Introduction to optical mineralogy, Oxford University Press, 348 pp

Passchier CW, Trouw RAJ (1996) Microtectonics. Springer, Berlin, p 289

Prikryl R (2001) Some microstructural aspects of strength variations in rocks. Int J Rock Mech Mining Sci 38:671-682

Smith MR, Collis L (eds) (2001) Aggregates: sand, gravel and crushed rock aggregates for construction purposes. Geological Society, London, Engineering Geology Special Publication No. 17

Sims I, Nixon P (2003) RILEM recommended test method AAR-1: detection of potential alkali-reactivity of aggregates-petrographic method. Mater Struct/Matér Construct 36:480-496 